\title{
Sodium aurothiomalate does not block interleukin production in rabbits
}

\author{
YEHUDA ZUROVSKY, 'HELEN P LABURN, ' DUNCAN MITCHELL,' \\ AND ANGELA RUCK²
}

From the Departments of ${ }^{\prime}$ Physiology and ${ }^{2}$ Medical Biochemistry, University of the Witwatersrand Medical School, Johannesburg 2193, South Africa

SUMMARY Gold salts may attenuate inflammatory processes by inhibiting interleukin 1o production. It is shown that sodium aurothiomalate does not act as an antipyretic after intravenous injection of two pyrogens into rabbits. Consequently, it cannot suppress interleukin $1_{\circ}^{\circ}$ production, a conclusion confirmed by an in vitro lymphocyte activating factor assay. Chronic ${ }^{5}$ sodium aurothiomalate treatment, however, did depress the blood leucocyte count significantly.

Key words: fever, inflammation, gold salts.

Gold treatment has been used in the management of rheumatic disease for most of this century, and yet its mechanism of action has not been established. ${ }^{12}$ In rheumatoid arthritis gold alters the function of phagocytes at the site of inflammation. ${ }^{3-5}$ Phagocytes play a major part in chronic inflammatory reactions through their capacity to ingest and degrade materials ${ }^{6}$ and to secrete a number of biologically active substances, ${ }^{78}$ which appear to mediate the inflammation. Gold particles accumulate in synovial macrophages ${ }^{13}$ and inhibit lysosomal enzyme activity. ${ }^{5}$ Mononuclear phagocytic activity is suppressed in patients with rheumatoid arthritis who receive gold treatment. ${ }^{9}$ Also, prolonged incubation with sodium aurothiomalate reduces the function of human mononuclear phagocytes as accessory cells in the induction of cellular immune responses in vitro. ${ }^{4}$

We do not know whether gold compounds also interfere with the capacity of phagocytes to secrete mediators of inflammation, including the plenipotentiary mediator interleukin 1 (IL1). ${ }^{10}$ Apart from its role in inflammation, IL1 is an essential intermediate in the genesis of fever. ${ }^{10}$ If gold salts indeed inhibit IL1 synthesis or release, as has been suggested for the salt auranofin, ${ }^{11}$ then they should act as antipyretics. We have investigated whether sodium aurothiomalate, a salt commonly used in gold treatment, acts as an antipyretic after intravenous

Accepted for publication 29 October 1987.

Correspondence to Professor Duncan Mitchell. Department of Physiology. University of the Witwatersrand Medical School. Parktown 2193. Johannesburg. South Africa. injection of pyrogens in conscious rabbits. We haves also investigated the effect of aurothiomalate in vitro on rabbit monocytes stimulated with endotoxin.

\section{Materials and methods}

In vivo investigations were carried out on New? Zealand White rabbits of either sex (mass 2-5 kg) conscious and restrained in conventional rabbit stocks. Rectal temperature was measured with⿳⺈ indwelling copper-constantan thermocouples, ando was monitored for at least an hour before injection. of pyrogens or placebo solutions into an ear mar-8 ginal vein. Temperature was measured for four hours after injections.

All experiments took place at an ambient temper $\rightarrow$ ature of between $21^{\circ} \mathrm{C}$ and $24^{\circ} \mathrm{C}$, and at the same time of day, with pyrogen injections taking place ato about 1100 .

\section{Results}

Fig. 1 shows results for rabbits given daily intrace muscular injections of $2 \mathrm{mg}$ sodium aurothiomalated (Maybaker, SA) for four weeks. These rabbits therefore received a total of $56 \mathrm{mg}$ of aurothiomalate, a dose comparable with the human thera용 peutic dose, per kilogram of body mass. ${ }^{1}$ Immediatel $\$$ after the four weeks of aurothiomalate treatmen $\$$ the rabbits were given an injection of a pyrogeno either endotoxin (lipopolysaccharide (LPS) extracte from Salmonella typhosa, Difco, $0.08 \mu \mathrm{g} / \mathrm{kg}$ ) of 


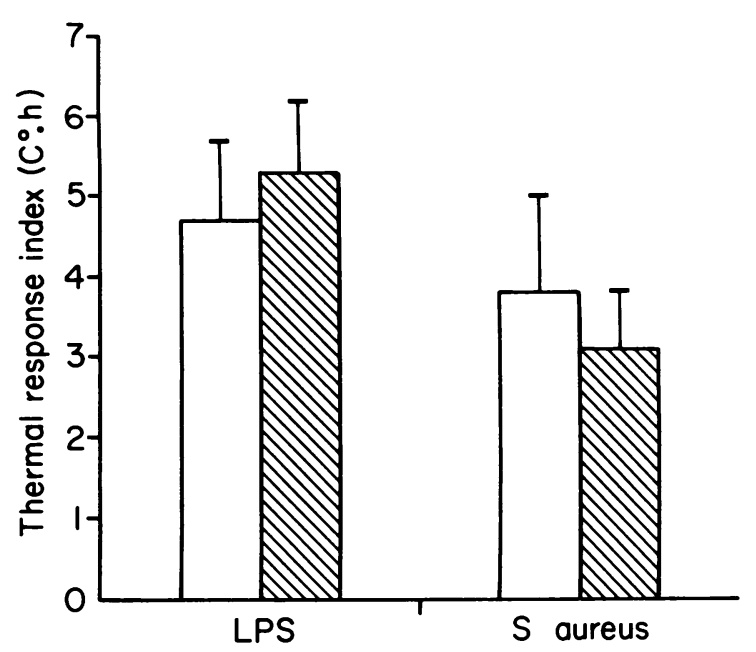

Fig 1 Thermal response index $\left({ }^{\circ} \mathrm{C} . h\right)$ of rabbits after intravenous injection of $0.08 \mu \mathrm{g} / \mathrm{kg}$ endotoxin (lipopolysaccharide) and of $5 \times 10^{7}$ organisms of killed Staphylococcus aureus with (hatched) and without (open) daily treatment of $2 \mathrm{mg}$ sodium aurothiomalate for four weeks before pyrogen injection. The mean of the four hour thermal response index $(S D)$ is shown, with $n=5$ for lipopolysaccharide and $n=3$ for $S$ aureus.

Staphylococcus aureus (Calbiochem, $5 \times 10^{7}$ killed organisms). Control animals received the pyrogens without aurothiomalate pretreatment. The four hour thermal response index, calculated as described by Clark and Cumby, ${ }^{12}$ was used as an index of fever. The thermal response index is the time integral $\left({ }^{\circ} \mathrm{C} . h\right)$ of the rise in rectal temperature after injection of pyrogen.

For both pyrogens the thermal response index in rabbits treated with aurothiomalate was not significantly different from that for control rabbits ( $p>0.05$, unpaired $t$ test). Also, the fevers did not differ significantly in either peak amplitude or latency of onset. Chronic aurothiomalate treatment, therefore, had no significant antipyretic effect.

Acute aurothiomalate treatment also had no antipyretic effect. In six other rabbits we injected 10 $\mathrm{mg}$ of sodium aurothiomalate directly into the ear vein together with $1 \mu \mathrm{g}$ of endotoxin. The fever which ensued had the same latency and peak amplitude as the fever evident when the endotoxin was injected alone. A potential antipyretic action of aurothiomalate could have been masked if intravenous aurothiomalate itself were pyrogenic. Intravenous aurothiomalate $(10 \mathrm{mg})$ on its own, however, had no significant effect on rectal temperature.

As aurothiomalate, in two dosage regimens, had no significant antipyretic effect against two different pyrogens we concluded tentatively that it did not inhibit ILl production. To confirm our conclusions we measured IL1 production by rabbit monocytes in vitro. Monocytes were isolated with Hypaque-Ficole (Pharmacia). Cell viability was determined by the trypan blue method. Then about $10^{6}$ viable cells were incubated with each of three concentrations of sodium aurothiomalate $(2 \cdot 5,25$, and $100 \mu \mathrm{g} / \mathrm{ml})$ in 1 $\mathrm{ml}$ of RPMI $1640-10 \%$ fetal calf serum for 96 hours at $37^{\circ} \mathrm{C}$ in an atmosphere of $95 \%$ air, $5 \% \mathrm{CO}_{2}$, and $100 \%$ humidity. All incubations were carried out in triplicate. After the incubation period the cells were harvested and cell viability again determined. The harvested cells then were stimulated for one hour with endotoxin $\left(0 \cdot 5-1 \mu \mathrm{g} / 10^{5}\right.$ cells), washed, and resuspended in fresh medium. The suspension was centrifuged 24 hours later, and the supernatants were collected and tested for IL1 activity by the lymphocyte activating factor assay. ${ }^{13}$

The lymphocyte activating factor assay showed IL1 activity only in supernatants from control monocytes and those incubated with the low concentration of sodium aurothiomalate $(2 \cdot 5 \mu \mathrm{g} / \mathrm{ml})$, in which ILl activity was $20 \%$ lower than control. The Table shows why there was an apparent reduction of IL1 at $2.5 \mu \mathrm{g} / \mathrm{ml}$ concentration and an absence of activity at higher concentrations: even at low concentration aurothiomalate killed almost all the monocytes. Indeed, when ILl production was expressed per viable monocyte, production was enhanced in the presence of aurothiomalate.

Was the production of IL1 per viable leucocyte also enhanced in vivo? We measured the total leucocyte count in the rabbits before (mean (SE) 7.2 $\left.(1.5) \times 10^{9} / 1\right)$ and after $\left(3.7(1.6) \times 10^{9} / 1\right)$ treatment with $2 \mathrm{mg}$ of intramuscular aurothiomalate a day for four weeks. The decline was highly significant $(\mathrm{p}<0.01, \mathrm{n}=5$, unpaired $t$ test $)$. The finding that fever was unaffected despite a halving in leucocyte count leads us to believe that, if anything, IL1 production per leucocyte was enhanced in vivo too.

Table Changes in number of viable rabbit monocytes (mean of three runs each) after incubation for 96 hours with varying concentrations of sodium aurothiomalate

\begin{tabular}{|c|c|c|c|}
\hline \multirow{2}{*}{$\begin{array}{l}\text { Aurothiomalate } \\
\text { concentration } \\
(\mu \mathrm{g} / \mathrm{ml})\end{array}$} & \multicolumn{3}{|c|}{ No of viable cells/ul } \\
\hline & $\begin{array}{l}\text { Before } \\
\text { incubation }\end{array}$ & $\begin{array}{l}\text { After } \\
\text { incubation }\end{array}$ & $\begin{array}{l}\text { Change } \\
(\%)\end{array}$ \\
\hline () & 69() & 6.50 & 6 \\
\hline $2 \cdot 5$ & 880 & 87 & 90 \\
\hline 25 & 1120 & 43 & 96 \\
\hline $1(x)$ & 820 & 22 & 97 \\
\hline
\end{tabular}




\section{Discussion}

Scdium aurothiomalate inhibits phagocytic activity in inflammation. ${ }^{1+16}$ In vivo studies have shown that sodium aurothiomalate inhibits phagocytosis by both polymorphonuclear leucocytes and macrophages, ${ }^{17}$ and subsequent in vitro studies have confirmed the inhibition of phagocytic activity of peripheral blood monocytes and tissue macrophages. ${ }^{18} 19$ Phagocytic cells release IL1, which is a mediator of inflammation. so one may reasonably suppose that sodium aurothiomalate would inhibit ILl release. If so, it should act as an antipyretic because ILl also is an essential intermediate in fever. ${ }^{10}$ Our results do not support this supposition. We showed that the rabbit's response to intravenous infection of the pyrogens endotoxin and $S$ aureus was the same with or without sodium aurothiomalate treatment, whether aurothiomalate was given simultaneously with pyrogen or daily for four weeks before the pyrogen. In vitro, rabbit monocytes still produced IL1 after incubation with a concentration of sodium aurothiomalate that killed about $90 \%$ of the cells.

In vivo, sodium aurothiomalate treatment for four weeks reduced the number of circulating leucocytes by about $50 \%$. In addition to inhibiting some of the inflammatory effects of leucocytes, gold therefore appears to cause a net decrease in the total number of circulating leucocytes. Leucopenia in humans after sodium aurothiomalate treatment has been noted previously. ${ }^{20}$ The reduction in leucocyte count did not affect the animals" ability to develop fever, an observation which we have made in other circumstances. $^{21}$ It may be that aurothiomalate enhanced the release of ILl from the surviving leucocytes, as indicated by our in vitro results.

We conclude that sodium aurothiomalate treatment, although it affects leucocyte count, does not affect fever, and therefore cannot inhibit IL1 production. This conclusion was supported by direct measurements of ILl production.

We thank Dr Patrick MacPhail for suggesting the investigation. Dr Steve Warner for advice concerning gold salts and the lymphocyte activating factor assay. Dr Roy Baynes for advice. and the South African Medical Research Council and the Council of the University of the Witwatersrand for financial support.

\section{References}

1 Vernon-Roberts B, Dore J L. Jessop J D. Henderson W J.
Selective concentrations and localization of gold in macrophages of synovial and other tissues during and after chrysotherapy in rheumatoid patients. Ann Rheum Dis 1976: 35: $477-86$.

2 Smith M D. Brooks P M. Gold compound in rheumatic discase. Med I Aust 1984: 140: 77-81.

3 Ghadially F N. Orvischat A F. Mitchell D M. Lltrastructural changes produced in rheumatoid svnovial membranc by chrisotheraps. Ann Rheum l)is 1976: 35: 67-72.

+ Lipsky P E. Ziff M. Inhibition of antigen and mitogen induced है human lymphocyte proliferation by gold compounds. J ('lin $\overrightarrow{0}$ Invest 1977: 7: 455-66.

5 Persellin R H. Ziff M. Effect of gold salt on lysosomal enzymes $\overrightarrow{\vec{\omega}}$ of the peritoneal macrophage. Arthritis Rhetim 1966: 9: 57-65.

6 Page R C. Davies P. Allison A C. Participation of mononuclear d phagocytes in chronic inflammatory disease. Journal of the Reticuloendothelial Society 1974: 15: 413-38.

7 Davis P. Allison A C. The macrophages as a secretory cell in. chronic inflammation. Agents Actions 1976; 6: 60-74.

$\&$ Unanue E R. Secretory function of mononuclear phagocytes. O Am J Pathol 1976: 83: 396-417.

9 Jessop J D. Vernon-Roberts B. Harris J. Effects of gold salts and prednisolone on inflammatory cells. I. Phagocytic activity of macrophages and polymorphs in inflammatory exudatese studied by a skin window technique in rheumatoid and control patients. Ann Rheum 1)is 1973: 32: 29+3(1).

10 Dinarcllo $C$ A Interleukin-1. Rev Infect Dis 1984: 6: 51-45

11 Hanna N. Di Martino M. Griswold D E. Poste G. Immunologyo of auranofin. an overview. In: Capell H A. Cole D S. Manghani. K K. Morris R W. eds. Auranofin. Amsterdam: ExcerptaO Medica. 1983: 60-70.

12 Clark $(\mathrm{j} W$. Cumbs H R. The antipuretic effect of indomethat cin. J Physiol 1975: 248: 625-38.

13 Gery I Gershon R K Waksman B H Potentiation of Tlymphocyte response to mitogens. I. The responding cell. J Exp $\mathbb{D}$ Med 1972: 136: 128-42

14 Lipsky P E. Ugai K. Ziff M. Alterations in human monocvtc $\bar{O}$ structure and function induced by incubation with gold sodium 3 thiomalate. Journal of Rheumatology. Supplement 1979: 6: $130-6$.

15 Lipsky P E. Ziff M. The effect of D-penicillamine on mitogeninduced human lymphocyte proliferation: svnergistic inhibition by D-penicillamine and copper salts. J Immunol 1978: 120:? li(x)6-13

16 Ugai K. Ziff M. Lipsky P E. Gold induced changes in the morphology and functional capabilities of human monocytes. Arthritis Rheum 1979; 22: 1352-60.

17 Jessop J D Vernon-Roberts B. Harris J. Effects of gold salts and prednisolone on inflammatory cells. II. Suppression of inflammation and phagocytosis in the rat. Ann Rheum Dis 1973:D 32: 301-7.

18 Jessop J D. Wilkins M. The effect of gold salts on the phagocyte activity of synovial macrophages in organ culture. Journal of 0 Rheumatology. Supplement 1979: 6: 137-42

19 Viken K E. Lamvik J O. Effect of aurothiomalate on human nuclear blood cells cultured in vitro. Acta Pathologica et $\mathrm{\omega}$ Microbiologica Scandinavica, Section C, Immunology 1976; 84: 419-24.

2) Patterson H R. Gustafsan E R. Sheridan E S. Current druge handbook 1984-1986. Philadelphia: Saunders. 1986: 242.

21 Lissoos T. Schwellnus M. Zent C. et al. Leucocyte pyrogen? synthesis in protein malnutrition. South African Journal of $\square$ Science 1982: 78: 81 . 